\title{
Bond Effects between Concrete and Steel Bar Using Different Diameter Bars and Different Initial Crack Width
}

\author{
Papa Niane Faye, ${ }^{1}$ Yinghua Ye, ${ }^{1}$ and Bo Diao ${ }^{1,2}$ \\ ${ }^{1}$ School of Transportation Science and Engineering, Beihang University, Beijing 100191, China \\ ${ }^{2}$ State Laboratory of Subtropical Building Science, South China University of Technology, Guangzhou 510640, China
}

Correspondence should be addressed to Papa Niane Faye; shakurfaye@hotmail.com

Received 4 February 2017; Accepted 16 March 2017; Published 2 April 2017

Academic Editor: Peng Zhang

Copyright (C) 2017 Papa Niane Faye et al. This is an open access article distributed under the Creative Commons Attribution License, which permits unrestricted use, distribution, and reproduction in any medium, provided the original work is properly cited.

\begin{abstract}
The importance of an accurate simulation of service conditions in the bond performance of reinforced concrete structures in coastal regions is highlighted. Four widths of initial crack of $0,80,150$, and 210 microns were artificially made by inserting slice into bond specimens during concrete casting. Three bar diameters of $10 \mathrm{~mm}, 14 \mathrm{~mm}$, and $18 \mathrm{~mm}$ were selected. At 28 days, the bond specimens were exposed to the environment of wet-dry cycles of seawater and atmosphere for another 90 days. The pull-out test was then conducted and chloride contents were tested at crack area along $40 \mathrm{~mm}$ depth. Results show that, for the specimen with $10 \mathrm{~mm}$ bar diameter, cracks width of less than 80 microns vanished rapidly during wet-dry cycles; for other specimens, cracks width of 100-150 microns decreased slightly. However the cracks of width more than 200 microns increased gradually; the chloride content decreased along the depth of concrete, and the chloride content increased as the widths of initial cracks increased or as the bar diameters increased. The ductility of bond specimens decreased as the diameter increased.
\end{abstract}

\section{Introduction}

Chloride attack is one of the most severe durability problems for the marine reinforced concrete structures [1]. The chloride penetration of concrete was affected in many ways, including physical, chemical, and mechanical such as permeability, cement binding, and cracking (both internal and external) [2]. The particles penetrate the concrete structures depending on the driving force of the process and the nature of the transported matter, where aggressive medium was transported through concrete by diffusion, absorption, and permeation [3]. It was found that the natural process of chloride ingress in concrete structures takes long time [1]. Under the same service conditions, reinforced concrete flexural members located in marine environments may become unserviceable before becoming unsafe [4]. Corrosion of steel bars embedded in concrete becomes a worldwide problem that affects durability of reinforced concrete structures [5].

In reinforced concrete structures, concrete with fighting against compressive loads plays also the role of protection of the steel bars to the external environment. A good force transfer between the two materials can therefore only be achieved by an interaction between both materials through bond between the reinforcement bars and the concrete [6]. Such attributes ensure the durability and serviceability of the structure.

The concrete crack can be classified into the following: a crack due to load applied on structures or natural phenomena on its environment. The nonloaded cracks, especially shrinkage cracks, have more important practical significance [7]. $\mathrm{Li}$ found that when the crack width is greater than $0.1 \mathrm{~mm}$, the effect of different concrete covers on chloride penetration, and hence the corrosion initiation, is very small [8]. At a crack width of $0.2 \mathrm{~mm}$, the difference between the initiation times as determined by chloride content and inspection is only $6 \%$ [9]. Limit of crack width depending on the environment was made by standards and most design codes and standards. However, ACI 318 (ACI Committee 318 1999) and BS 8110 (British Standards 1997) prescribe the maximum permissible crack width to be $0.3 \mathrm{~mm}$ for concrete structures [10]. If crack width exceeded $0.3 \mathrm{~mm}$, structures might fail and safety problems might as well start. Failure does not necessarily imply structural collapse but includes loss of serviceability, characterized by cracking, spalling, debonding, and excessive 
TABLE 1: Concrete mixture composition $\left(\mathrm{kg} / \mathrm{m}^{3}\right)$.

\begin{tabular}{ccccccccc}
\hline & Water & Cement & Fly ash & Sand & Aggregate & Water reducer & Air entertainer \\
\hline Quantity & 184 & 460 & 53 & 609 & 1130 & 3.94 & 100.61 \\
\hline
\end{tabular}

deflection [8], so the purpose of design must be fully reflected in the design of specific provisions focused on structural strength and durability [11].

Marine environment contributes to chemical reactions. When carbon dioxide diffuses into concrete in the presence of water, it reacts with calcium hydroxide to form calcium carbonate $[3,12]$. Pommersheim and Clifton demonstrated that in seawater degradation mechanisms can be due to the reaction considered involving the replacement of $\mathrm{Ca}(\mathrm{OH}) 2$ in concrete by gypsum ( $\mathrm{CaSO} 4 \cdot 2 \mathrm{H} 20)$, and an expansive process involves the reaction of sulfate ions with calcium aluminates hydrate that gives ettringite (3 CaO. A1203.3 CaSO4.31 H20) [13].

A pull-out load was applied to a reinforcement bar embedded in concrete; the resistance which was defined as bond strength between concrete and reinforcement was tested and it was an important factor for RC structures [14]. Using a numerical approach, De Almeida Filho and El Debs explained the load versus slip behavior of the pull-out test [15]. Kabir and Islam affirmed that bond performance of reinforced concrete is important in the study of load transfer mechanism from concrete to inner reinforcing bar and vice versa [16]. On one hand, bond strength was influenced by curing conditions [14], concrete compressive strength $[17,18]$, concrete cover, embedded length, preflexural crack length, chemical adhesion, and friction [16]. On the other hand, bond strength was influenced by mechanical interlock by ribs and diameter of reinforcement bars [19, 20]. The bond strength was specifically expressed as the function of the applied load, bars diameter, and embedded length [21]. Ductility is the ability of the structure to absorb large energy and produce certain deformation without destroying under a shock or vibration load [22]. The relationship among bonds between concrete and steel bars, durability, and chlorite penetration rate are nowadays structural engineering challenges.

The combined effects of initial crack width, diameter of steel bar sand environments on the bond strength, and distribution of chloride ion were experimentally investigated. Three diameters of steel bars, four initial crack widths, and two types of environments were selected. The relationship between different diameters embedded in cracked concrete, chloride permeability, and bond strength between different diameter and different crack width of concrete after 90 days of wet-dry cycles of seawater were studied.

\section{Specimens and Test Program}

Good performances and high quality of concrete mixtures were designed here. All experiments were conducted in structural laboratory of Beihang University.

2.1. Concrete Composition and Properties. This was a concrete mixture with normal Portland cement P.O.42.5, aggregate of maximum $10 \mathrm{~mm}$, medium sand 2.6, fly ash, and high performance polycarboxylate super plasticizer (standard) HY801 (water-reducer) admixture. The ratio of water/cement was 0.4 , and the air content was $5.7 \%$. The compressive strength of concrete prism with sizes of $100 \mathrm{~mm} * 100 \mathrm{~mm} *$ $300 \mathrm{~mm}$ was around $39.3 \mathrm{MPa}$ and tested at the age of $28 \mathrm{~d}$. The concrete mixture composition in kilograms per cubic meter is given in Table 1.

2.2. Specimen Design. The bond specimens between concrete and steel bars for pull-out test were designed with different steel bars of diameter $10 \mathrm{~mm}, 14 \mathrm{~mm}$, or $18 \mathrm{~mm}$. As shown in Figure 1, a reinforcement bar was embedded centrally into concrete block, and the embedded length was 5 times the diameter, that is, $50 \mathrm{~mm}, 70 \mathrm{~mm}$, and $90 \mathrm{~mm}$. PVC tubes were used here to ensure that only shear stress appeared between concrete and steel bar on pull-out test.

The chloride ingress in concrete with cracks was experimentally studied by [23]. They used to insert 3 sheets of $0.2 \mathrm{~mm}, 0.3 \mathrm{~mm}$, and $0.5 \mathrm{~mm}$ in the specimen for around 4 hours and then fixed the insertion depth of depths $20 \mathrm{~mm}$, $30 \mathrm{~mm}$, and $50 \mathrm{~mm}$. Prisms of dimension $(100 \times 100 \times$ $150 \mathrm{~mm}$ ) were adopted in this experimentation. In order to conform to our research plan based on the crack width control, two models of crack simulations were tried; the first model was similar to Marsavina's model [23]; different plate sheets of thickness of $0.05 \mathrm{~mm}, 0.1 \mathrm{~mm}$, and $0.2 \mathrm{~mm}$ were inserted into half depth of the concrete section; duration time was 4 hours. The second model: plate sheet of thickness $0.05 \mathrm{~mm}$ was inserted into the steel bars and duration times were $3 \mathrm{~h}, 4 \mathrm{~h}$, and $5 \mathrm{~h}$ before they were removed, respectively. The initial crack widths were tested 2 days later. During the measurement it was observed that the average crack width gotten from the second method with the same plate sheet and different duration times gives approximately the desired widths of cracks and 4 different classes of crack widths including $0 \mathrm{~mm}$. The result shows that the largest width (around 200 microns) of crack was obtained after $5 \mathrm{~h}$ of plate sheet insertion. The crack lengths for two models were the same equal to $100 \mathrm{~mm}$ (size of the block) and the depths of cracks which were equal to concrete cover were $45 \mathrm{~mm}$, $43 \mathrm{~mm}$, and $41 \mathrm{~mm}$ for $10 \mathrm{~mm}, 14 \mathrm{~mm}$, and $18 \mathrm{~mm}$ diameters of steel bars, respectively. The details of specimens and tested groups are given in Tables 2, 3, and 4 .

30 specimens of bond between concrete and steel bars were designed and cast. The 30 bond specimens were divided into three sets on the basis of the diameter of steel bars. Each set of specimens was also divided into four groups based on the width of initial cracks and exposing environments. Four groups of initial cracks width were designed as 0 microns, 80 microns, 150 microns, and 210 microns. Two environments of wet-dry cycles and atmosphere were designed. Each group 

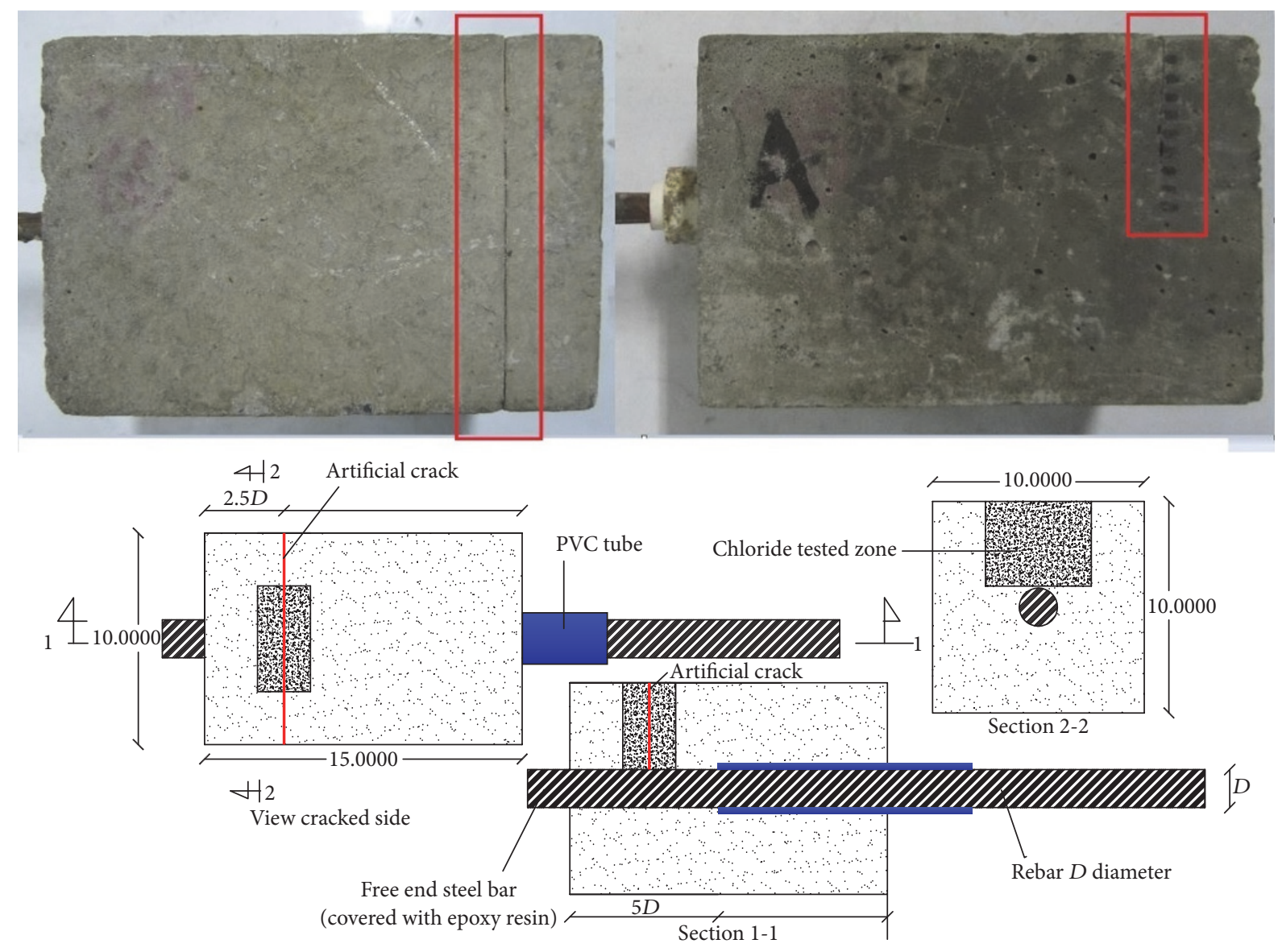

FIGURE 1: Detail of bond specimen for pull-out test crack design and sample design.

TABLE 2: Detailed information of bond specimens with $10 \mathrm{~mm}$ diameter bars.

\begin{tabular}{lccccc}
\hline & COD10RE & C0D10WD & C80D10WD & C150D10WD & C210D10WD \\
\hline Number of specimens & 2 & 2 & 2 & 2 & 2 \\
Design width of crack & 0 & 0 & 80 & Yes & Yes \\
Seawater & No & Yes & 3 & 4 & Yes \\
Plate sheet insertion time (hours) & 0 & 0 & 5 & 5 \\
\hline
\end{tabular}

TABLE 3: Detailed information of bond specimens with $14 \mathrm{~mm}$ diameter bars.

\begin{tabular}{lccccc}
\hline & COD14RE & C0D14WD & C80D14WD & C150D14WD & C210D14CW \\
\hline Number of specimens & 2 & 2 & 2 & 2 & 150 \\
Design width of crack & 0 & 0 & 80 & Yes & Yes \\
Seawater & No & Yes & 3 & 4 & Yes \\
Plate sheet insertion time (hours) & 0 & 0 & 5 \\
\hline
\end{tabular}

TABLE 4: Detailed information of bond specimens with $18 \mathrm{~mm}$ diameter bars.

\begin{tabular}{|c|c|c|c|c|c|}
\hline & COD18RE & C0D18WD & C80D18WD & C150D18WD & C210D18CW \\
\hline Number of specimens & 2 & 2 & 2 & 2 & 2 \\
\hline Design width of crack & 0 & 0 & 80 & 150 & 210 \\
\hline Seawater & No & Yes & Yes & Yes & Yes \\
\hline Plate sheet insertion time (hours) & 0 & 0 & 3 & 4 & 5 \\
\hline
\end{tabular}


TABLE 5: Crack width evolution of specimens with different bar diameters (80 microns).

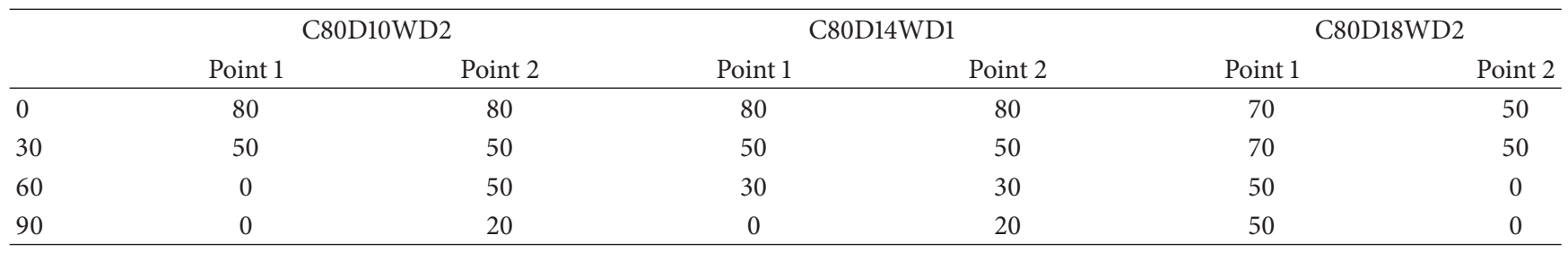

TABLE 6: Crack width evolution of specimens with different bar diameters (150 microns).

\begin{tabular}{|c|c|c|c|c|c|c|}
\hline \multirow{2}{*}{ Wet-dry cycles } & \multicolumn{2}{|c|}{ C150D10WD2 } & \multicolumn{2}{|c|}{ C150D14WD2 } & \multicolumn{2}{|c|}{ C150D18WD2 } \\
\hline & Point 1 & Point 2 & Point 1 & Point 2 & Point 1 & Point 2 \\
\hline 0 & 100 & 110 & 140 & 110 & 150 & 150 \\
\hline 30 & 100 & 110 & 140 & 110 & 130 & 140 \\
\hline 60 & 100 & 110 & 130 & 100 & 130 & 130 \\
\hline 90 & 100 & 100 & 130 & 100 & 130 & 130 \\
\hline
\end{tabular}

contained 2 bond specimens. They were exposed in two types of environment, that is, wet-dry cycles of seawater or atmosphere. The seawater was artificially made of $3 \% \mathrm{NaCl}$ and $0.34 \% \mathrm{MgSO} 4$. One of wet-dry cycles includes 8 hours of seawater immersion and 16 hours of atmosphere environment. After 90 cycles of wet-dry and 10 days of atmosphere environment, totally 100 days, the pull-out test was performed.

Tables 2, 3, and 4 give the detailed information of bond specimens sets (five groups), where the specimens are named following this rule. For example, for C0D10RE, C0D14RE, or C0D14WD, the number following C (C0, C80, C160, and C210) was the designed maximum width of initial crack in microns. The number following D (D10, D14, and D18) was the diameter of reinforcement bars. The last two words were the environment of specimen expositing (RE: reference environment (atmosphere), WD: wet-dry cycles of seawater).

2.3. Testing Procedures. All bond specimens were demolded after $24 \mathrm{~h}$ of casting and were cured under standard temperature and moisture conditions. At 28 days, except for the six reference specimens (in atmosphere), the remaining 24 bond specimens were exposed to wet-dry cycles environment. After every 30 wet-dry cycles, the crack widths of specimens were measured. Each cycle of wet-dry includes immersion in seawater for $8 \mathrm{~h}$ and in atmosphere for $16 \mathrm{~h}$. The alternating rounds of immersion in seawater and in atmosphere environment were repeated till 90 cycles and 10 days of atmospheric environment. The standard pull-out test was conducted on all bond specimens. The pull-out forces, relative slip displacement, and bond strength of every specimen were measured.

After pull-out testing, sample of plate concrete at crack was drilled on the specimen, that is, the chloride tested zone shown in Figure 1. The samples were then subdivided into 5 pieces along the depth of sample and chloride content was tested on that depth of $25 * 50 * 8 \mathrm{~mm}^{3}$ as shown in Figure 2 .

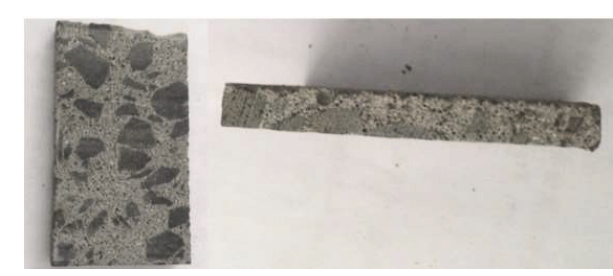

Figure 2: Concrete drilled slice $(2.5 \mathrm{~cm} / 5 \mathrm{~cm} / 8 \mathrm{~mm})$.

\section{Experiment Phenomenon and Results}

In this part, four main variables such as the crack evolution, the chloride content, ultimate tensile forces, and ultimate bond strength function with different diameter bars of $10 \mathrm{~mm}, 14 \mathrm{~mm}$, and $18 \mathrm{~mm}$ were experimentally investigated.

3.1. Evolution of Initial Crack on Bond Specimens. After cracks were made on bond specimens, two points on each crack were selected and fixed to measure the crack width during the wetdry cycles. The values of the two points on each crack width were measured after $0,30,60$, and 90 wet-dry cycles. Tables 5,6 , and 7 give tested values of crack widths during the wetdry cycles. All cracks here are artificially made by insertion of plate sheet at the earlier age of the concrete casting.

As shown in Table 5, testing results of two points on the same crack of bond specimens with bar diameters of $10 \mathrm{~mm}$ or $14 \mathrm{~mm}$ present reduction of crack width after 30 days of wet-dry cycles when the width was smaller than 80 microns. At the same moment, the testing results of specimens showed that crack width of the $18 \mathrm{~mm}$ diameter remained the same. The tested points of the crack width on the specimens with bar diameters of $10 \mathrm{~mm}$ or $14 \mathrm{~mm}$ decreased quickly as cycle number of wet-dry increased. At the same time the crack width of specimens with $18 \mathrm{~mm}$ diameter decreased slowly from initial crack width of 70 microns and 50 microns to 
TABLE 7: Crack width evolution of specimens with different bar diameters (210 microns).

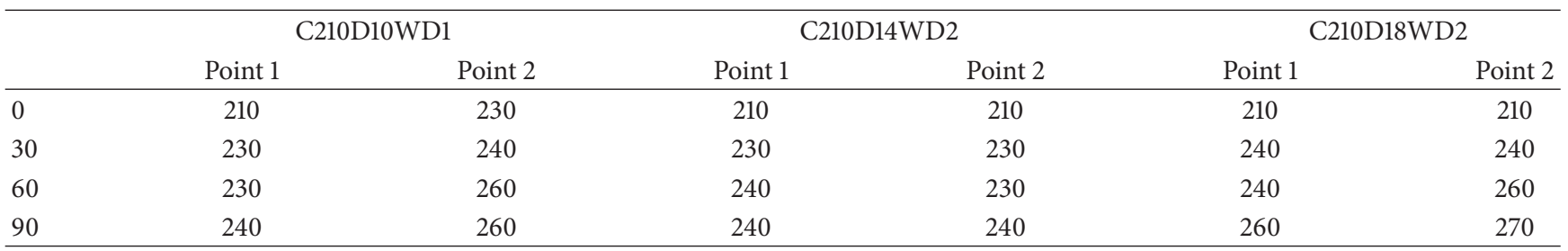

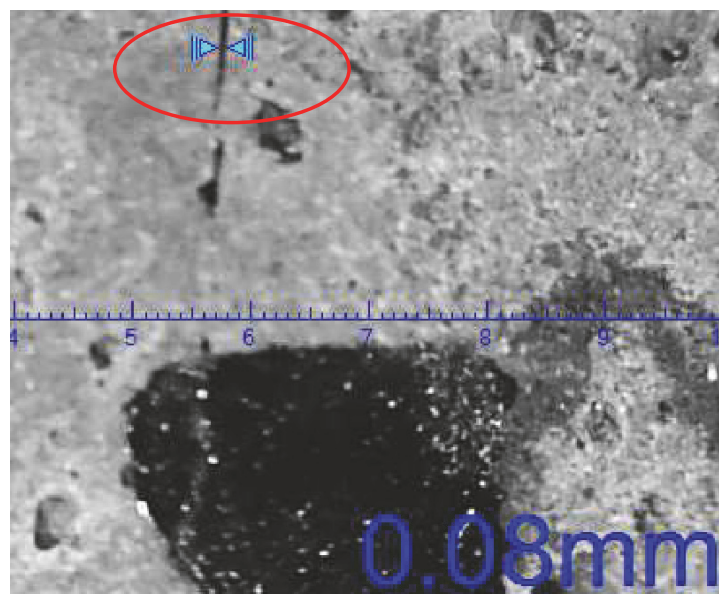

0 wet-dry cycles

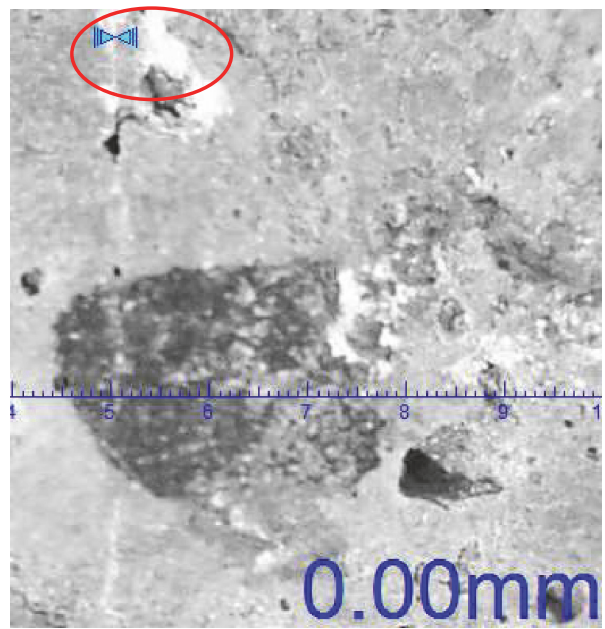

60 wet-dry cycles

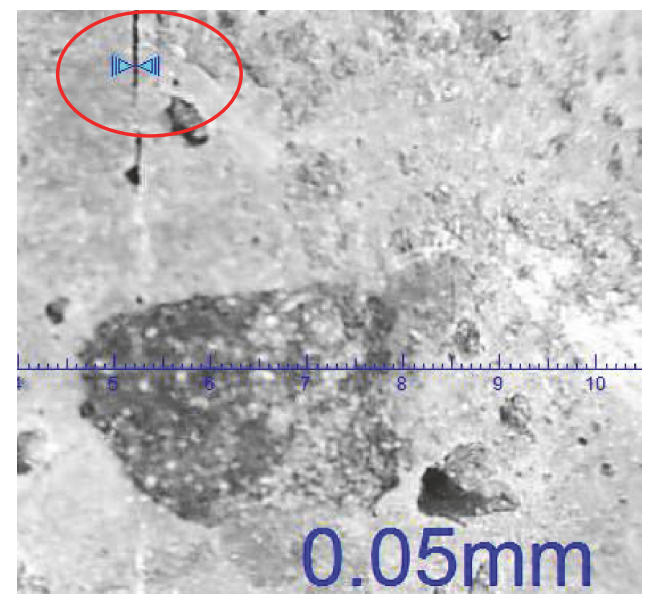

30 wet-dry cycles

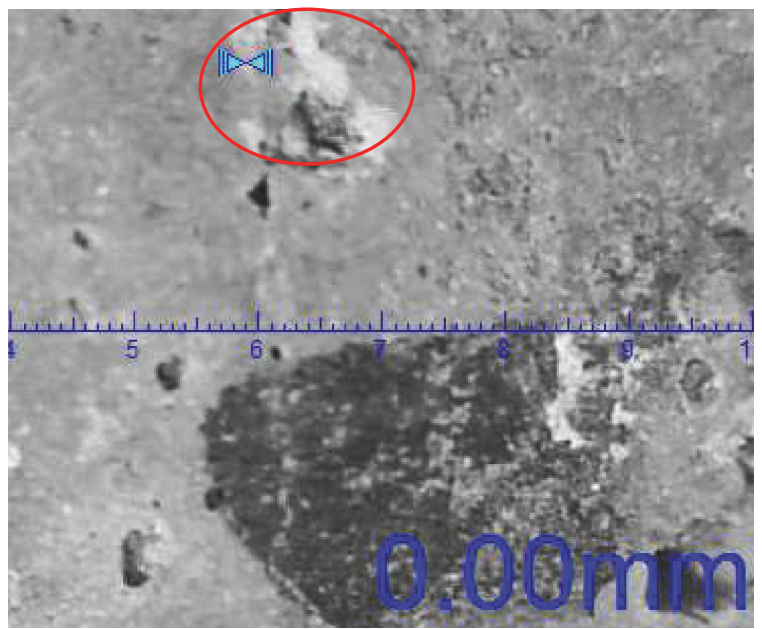

90 wet-dry cycles

FIGURE 3: Detail of crack evolution on C80D10WD2 point 1 with maximum crack width of 80 microns.

50 microns and 0 microns, respectively, after 90 days of wetdry cycles. Picture in Figure 3 gives a crack width decreasing illustration case of maximum crack width of 80 microns on $10 \mathrm{~mm}$ diameter bars point 1 . Small bar diameter creates an environment which makes microcracks around 80 microns decrease quickly.

When the initial crack widths were in the range of 100-150 microns, as shown in Table 6, test results of two points on each crack remained nearly the same during all environment exposure; this indicates that crack width changed a little when initial crack widths are in the range of 100-150 microns. Detail of crack evolution on C150D10WD point 2 with maximum crack width of 150 microns was shown in Figure 4.

Using the same procedure, the crack widths of 2 points on each crack were measured for the specimen when the initial crack widths were in the range of 210-230 microns. The specimens were chosen randomly and the testing result was shown in Table 7 and Figures 5 and 6.

To have more clear view on the evolution of initial crack widths, the testing results of all points 1 of the specimens were shown in Figure 5. As shown in Figure 5, the testing results of all points increased gradually as the cycle number of wet-dry 


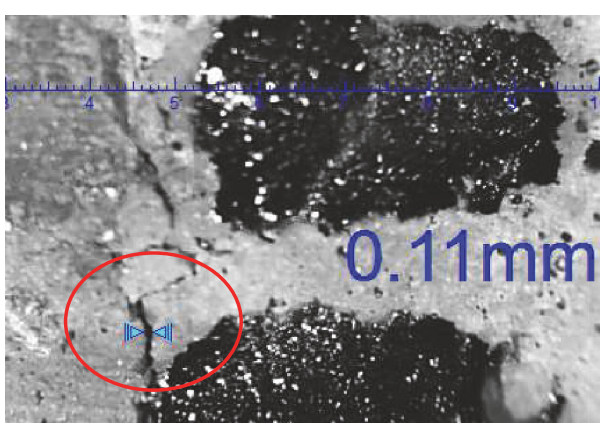

0 wet-dry cycles

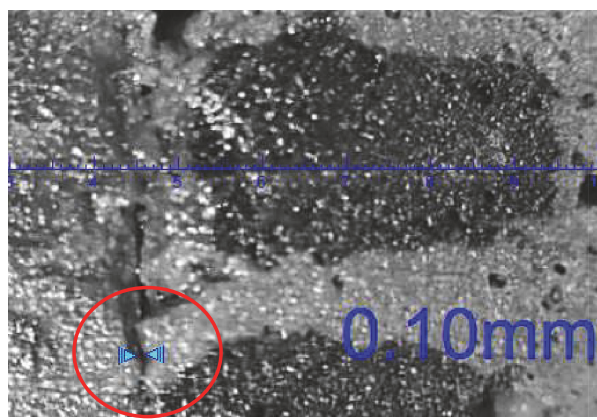

60 wet-dry cycles

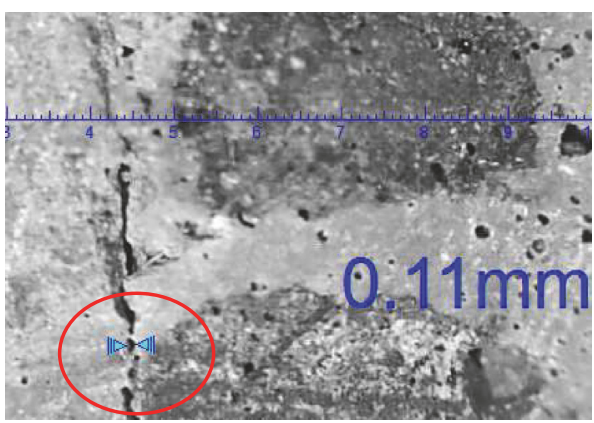

30 wet-dry cycles

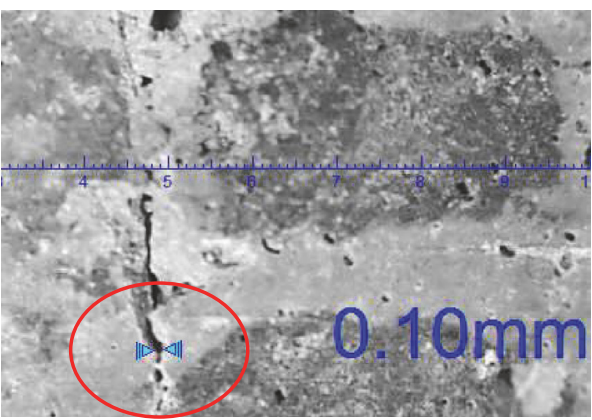

90 wet-dry cycles

FIGURE 4: Crack evolution of C150D10WD point 2.

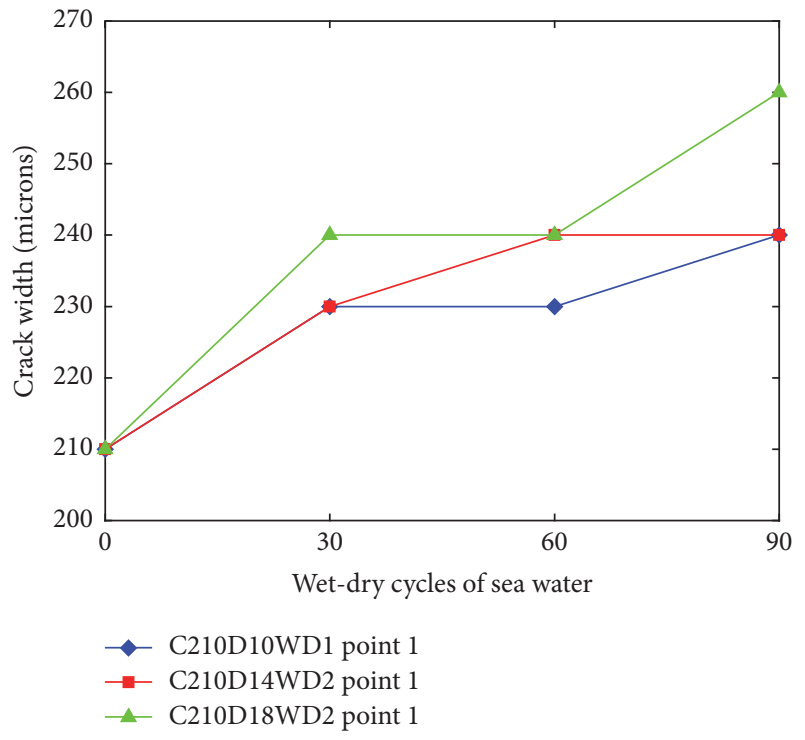

FIGURE 5: Relation between crack width and wet-dry cycles.

increased. The crack width of specimens with bar diameter of $18 \mathrm{~mm}$ increased more quickly from 210 microns to 260 microns. The large bar diameter hence impacted obviously on the evolution of crack width when the initial crack widths were in the range of 210-230 microns during the wet-dry cycles.

The experimental phenomenon of bond specimens with four classes of initial crack width of 0 microns, 80 microns, 150 microns, and 210 microns and three sizes of bar diameters of $10 \mathrm{~mm}, 14 \mathrm{~mm}$, and $18 \mathrm{~mm}$ has shown that when initial crack widths are around 80 microns all cracks tend to decrease. Nevertheless cracks on specimens with smaller diameter bars decreased faster than those with bigger diameters. When the cracks widths were in the range of 100-150 microns, the crack widths tend to stabilize or decrease a little; that is, their initial crack width was 100-150 microns and 100-130 microns after 90 wet-dry cycles. When the initial crack widths were in the range of 210-230 microns, all initial crack widths increased as the cycle number of wet-dry increased. Evolution of crack width showed that the speed of crack growth is directly proportional to the bar diameter and it is faster for larger diameters.

3.2. Ultimate Bond Strength. The ultimate pull-out forces were gotten by pull-out test and ultimate bond strength based on the embedment length and reinforcing bar diameter $[6,21]$ using the formula

$$
F_{b}=\frac{P_{u}}{\pi D L}
$$

where $F_{b}$ is the bond strength $\mathrm{MPa} ; P_{u}$ is the ultimate pullout force; $D$ is the diameter of reinforced bar; and $L$ is the embedment length which was assumed to be equal to 5 times the diameter.

The averages value of pull-out forces and bond strength of all specimens were listed in Table 8 . The result listed in Table 8 shows an interdependency between the bar diameter and bond strength, where the average bond strength of specimens decreased as the diameter increased; however there is no 


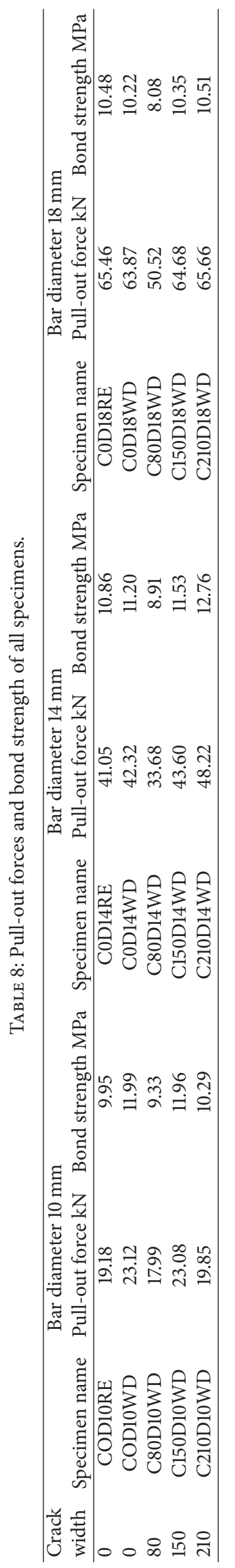




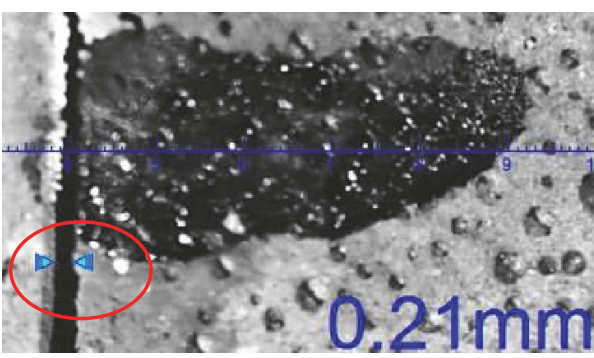

0 wet-dry cycles

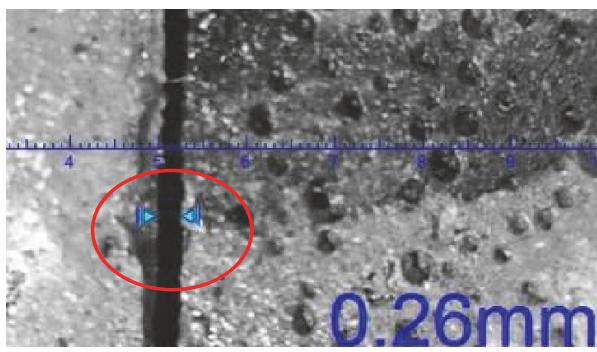

60 wet-dry cycles

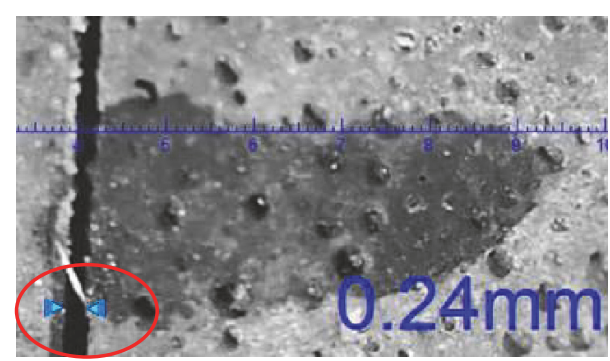

30 wet-dry cycles

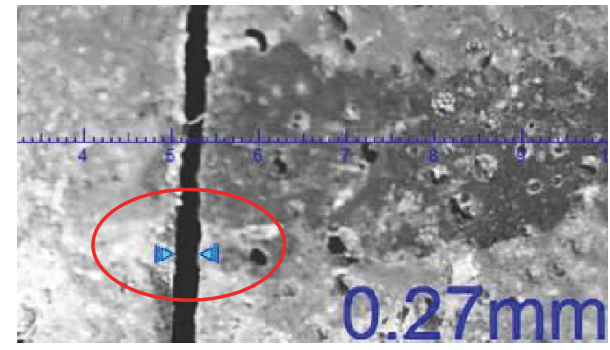

90 wet-dry cycles

FIGURE 6: Detail of crack evolution on C210D18WD2 point 2 with maximum crack width of 210 microns.

clear tendency of bond strengths for different widths of initial cracks.

For all specimens under wet-dry cycles of seawater and with different crack width, the pull-out forces showed no clear tendency, as shown in Figure 7. The bond strength of specimen with the same crack width but different bar diameters has shown a decreasing tendency when the bar diameter increased. Discontinuities are one of the most harmful types of damage to the durability of concrete structures [3]. It implies that when we made a microcrack less than 80 microns at the earlier age, the concrete crack might be closed and disappeared.

Figure 8 gives curves of pull-out force and relative slippage displacement from pull-out test for the specimens without initial cracks. As shown in Figure 8 and listed in Table 8, the combined effects of crack widths and bar diameters on the bond strength have shown no clear tendency; the ductility of specimens however decreased as the diameter increased.

3.3. Chloride Diffusion in Cracked Concrete. As it was previously mentioned, samples of concrete were drilled from the specimens and subdivided along the depth of sample into 5 pieces of slices and the thickness of each slice was about $8 \mathrm{~mm}$. The slice was smashed by pulverization and chloride content was tested. The test and analysed results of chloride contents for different bar diameter were listed in Tables 9, 10, and 11. The chloride contents and its incremental percentage of chloride content for the specimens with $10 \mathrm{~mm}$ bar diameter were listed in Table 9, where incremental percentage was the results compared with the chloride content of reference specimen. As listed in Table 9, the chloride content decreased as the depth of concrete increased. At the same depth, the chloride content increased as the width of initial cracks increased. As listed in Table 9, the incremental percentage of chloride content decreased quickly as the depth of concrete

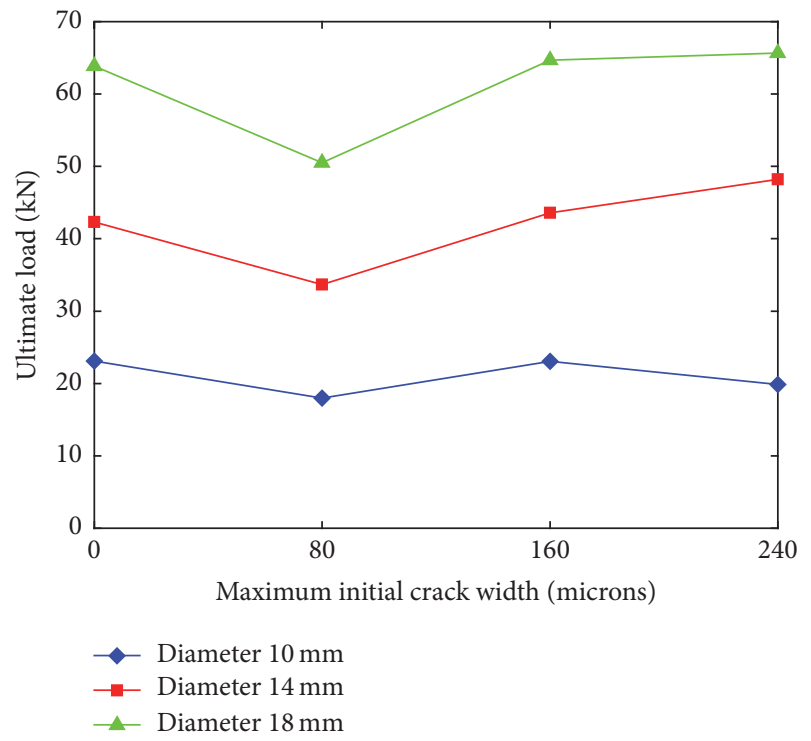

FIGURE 7: Relationship of initial crack width and ultimate pull-out force.

increased when the widths of initial cracks were less than 80 microns; the incremental percentage of chloride content however decreased slowly as the depth increased when the width of initial cracks was larger than 100 microns. As listed in Tables 10 and 11, the chloride content decreased as the depth of concrete increased and the chloride content increased as the width of initial cracks increased, in accordance with the same change rules for incremental percentage of chloride content.

The chloride content of specimens with different bar diameters and different width of initial cracks was shown in Figure 9. The chloride penetration in specimens was impacted by width of initial crack and bar diameters. 


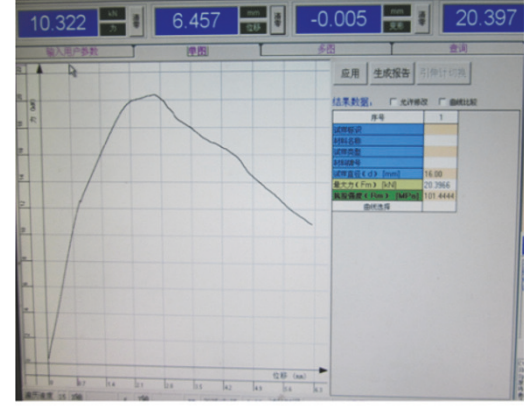

C0D10WD2

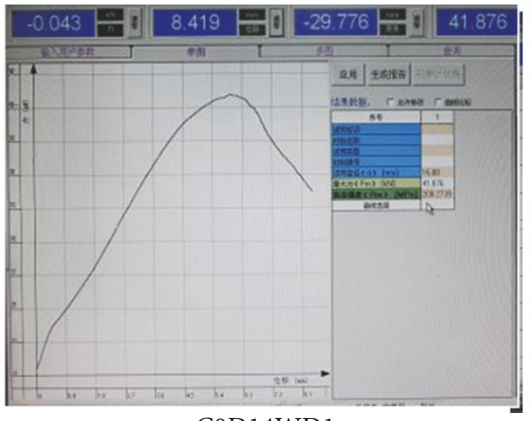

C0D14WD1

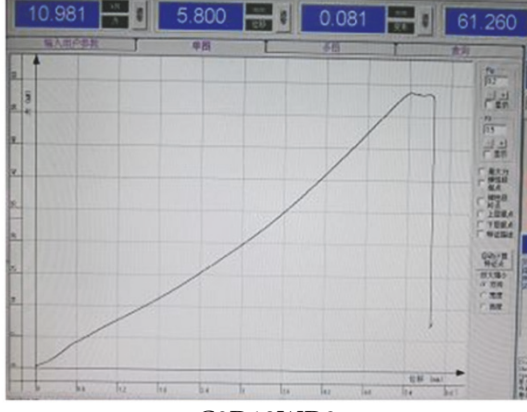

C0D18WD2

FIGURE 8: Curves of pull-out force-relative slippage displacement of C0D10WD2, C0D14WD1, and C0D18WD2.

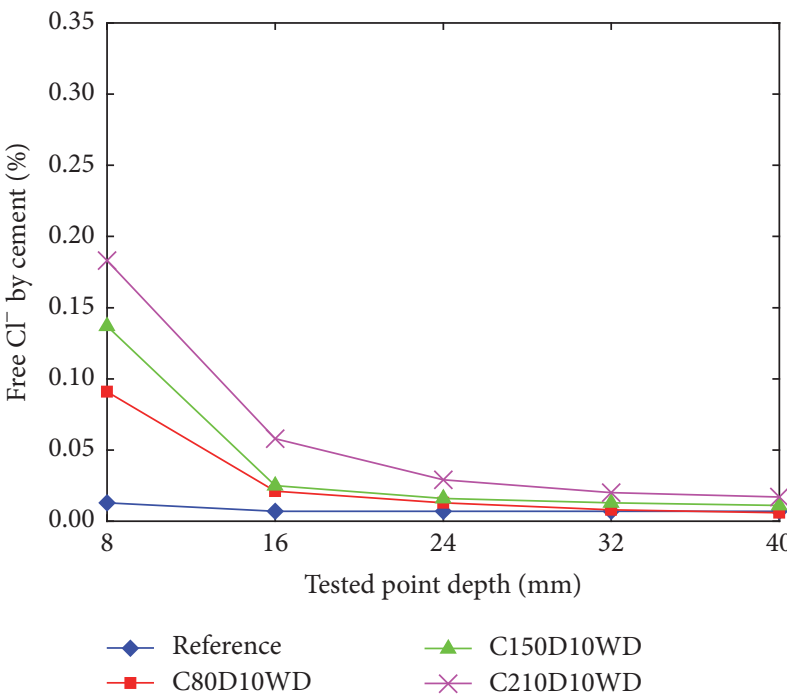

$10 \mathrm{~mm}$ diameter

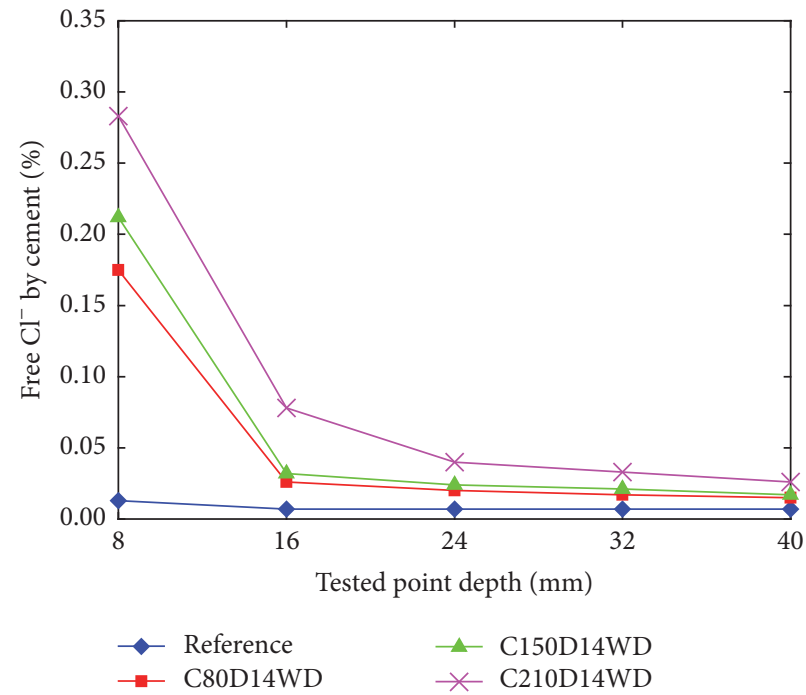

$14 \mathrm{~mm}$ diameter

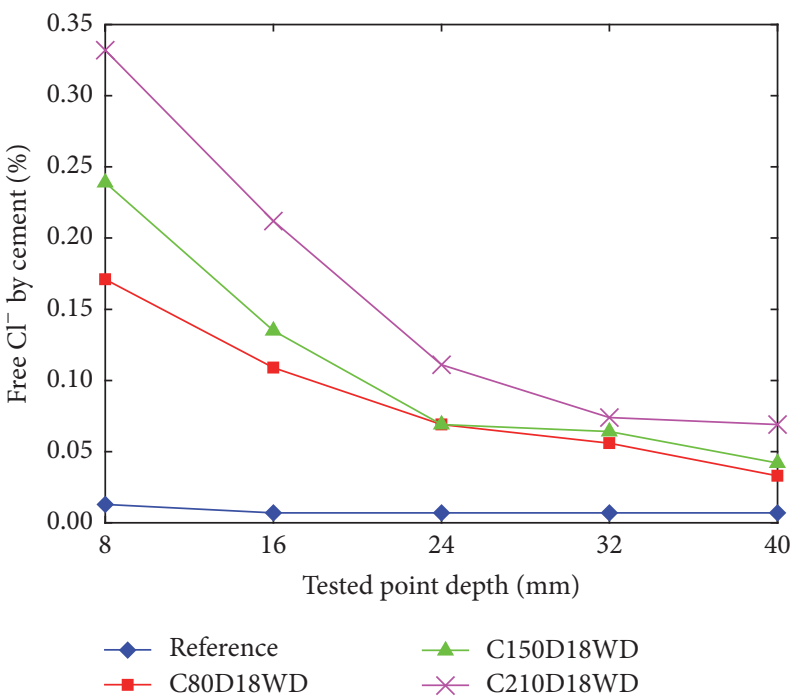

$18 \mathrm{~mm}$ diameter

FIGURE 9: Chloride content of specimens with different bar diameters and different width of initial cracks. 
TABLE 9: Chloride content and incremental percentage for specimens with $10 \mathrm{~mm}$ bars diameter.

\begin{tabular}{|c|c|c|c|c|c|c|c|}
\hline \multirow{2}{*}{ Depth } & \multicolumn{4}{|c|}{ Free (cl-) by cement (\%) } & \multicolumn{3}{|c|}{ Percentage of intercracks } \\
\hline & Reference & C80D10WD & C150D10WD & C210D10WD & $50-80$ & $100-110$ & $210-230$ \\
\hline 8 & 0.013 & 0.091 & 0.137 & 0.183 & $86 \%$ & $91 \%$ & $92 \%$ \\
\hline 16 & 0.007 & 0.021 & 0.025 & 0.058 & $67 \%$ & $72 \%$ & $88 \%$ \\
\hline 24 & 0.007 & 0.013 & 0.016 & 0.029 & $46 \%$ & $56 \%$ & $76 \%$ \\
\hline 32 & 0.007 & 0.008 & 0.013 & 0.020 & $8 \%$ & $46 \%$ & $65 \%$ \\
\hline 40 & 0.007 & 0.006 & 0.011 & 0.017 & $-9 \%$ & $36 \%$ & $56 \%$ \\
\hline
\end{tabular}

TABLE 10: Chloride content and incremental percentage for specimens with $14 \mathrm{~mm}$ bars diameter.

\begin{tabular}{|c|c|c|c|c|c|c|c|}
\hline \multirow{2}{*}{ Depth } & \multicolumn{4}{|c|}{ Free $(\mathrm{cl}-)$ by cement $(\%)$} & \multicolumn{3}{|c|}{ Percentage of intercracks } \\
\hline & Reference & C80D14WD & C150D14WD & C210D14WD & $50-80$ & $110-150$ & $210-230$ \\
\hline 8 & 0.013 & 0.175 & 0.212 & 0.283 & $93 \%$ & $94 \%$ & $95 \%$ \\
\hline 16 & 0.007 & 0.026 & 0.032 & 0.078 & $73 \%$ & $78 \%$ & $91 \%$ \\
\hline 24 & 0.007 & 0.020 & 0.024 & 0.040 & $65 \%$ & $71 \%$ & $83 \%$ \\
\hline 32 & 0.007 & 0.017 & 0.021 & 0.033 & $59 \%$ & $67 \%$ & $78 \%$ \\
\hline 40 & 0.007 & 0.015 & 0.017 & 0.026 & $53 \%$ & $59 \%$ & $73 \%$ \\
\hline
\end{tabular}

TABLE 11: Chloride content and incremental percentage for specimens with $18 \mathrm{~mm}$ bars diameter.

\begin{tabular}{lcccccc}
\hline \multirow{2}{*}{ Depth } & \multicolumn{2}{c}{ Free (cl-) by cement (\%) } & \multicolumn{3}{c}{ Percentage of intercracks } \\
& Reference & C80D18WD2 & C150D18WD2 & C210D18WD2 & $50-80$ & $100-110$ \\
\hline 8 & 0.013 & 0.171 & 0.239 & 0.332 & $92 \%$ & $95 \%$ \\
16 & 0.007 & 0.109 & 0.135 & 0.212 & $94 \%$ & $96 \%$ \\
24 & 0.007 & 0.069 & 0.069 & 0.111 & $90 \%$ & $90 \%$ \\
32 & 0.007 & 0.056 & 0.064 & 0.074 & $87 \%$ & $89 \%$ \\
40 & 0.007 & 0.033 & 0.042 & 0.069 & $79 \%$ & $83 \%$ \\
\hline
\end{tabular}

As shown in Figure 9, for the specimens with the same bar diameter, the chloride content decreased as the depth of concrete increased, and the chloride content increased as the width of initial crack increased. At the depth of $40 \mathrm{~mm}$, the chloride contents were nearly the same when the crack width was less than 80 microns and with $10 \mathrm{~mm}$ diameter. The chloride content equally increased quickly when the bar diameter increased from $10 \mathrm{~mm}$ to $18 \mathrm{~mm}$ and width of initial crack increased. This means that the penetration of chloride ion on bond specimens was significantly impacted by the interaction of bar diameters and width of initial cracks.

\section{Conclusion}

This paper presents an experimental study on the impact of the combined actions of wet-dry cycles, initial cracks, and different bar diameters on the cracks evolution, chloride penetration, and the bond strength of reinforced concrete specimens. The following conclusions can be drawn from the results of the current study:

(1) When the bond specimen is with small diameter of steel bars and with crack width less than 80 microns, after 90 days of wet-dry cycles of seawater, the cracks vanished rapidly compared to those with bigger diameter bars.

(2) When cracks width were in the range of 100-150 microns, after 90 days of wet-dry cycles of seawater, the width of cracks decreased slightly; however the cracks width increased if the crack widths were larger than 200 microns.

(3) After 90 days of wet-dry cycles of seawater, the chloride content decreased along the depth of concrete, and the chloride content increased as the widths of initial cracks or bars diameter increased.

(4) The combined effects of crack widths and bar diameters on the bond strength have shown no clear tendency in the current study; however the ductility of bond specimens decreased as the diameter increased.

\section{Conflicts of Interest}

The authors declare that there are no conflicts of interest regarding the publication of this paper. 


\section{Acknowledgments}

This work is part of the projects financially supported by the Chinese National Natural Science Foundation (NSFC) Grant no. 51578031 and by the open topics of State Key Laboratory of Subtropical Architecture Science (SKLSAS) in South China University of Technology (2016ZA03). The authors gratefully acknowledge the financial support received from the NSFC and SKLSAS.

\section{References}

[1] W. Xue, L. Zhang, Y. Xiong, J. Chen, and W. Jin, "Accelerating tests for the performance deterioration of concrete exposed to chloride media," Procedia Engineering, vol. 27, pp. 1635-1643, 2012.

[2] C. Q. Li and R. E. Melchers, "Time-dependent risk assessment of structural deterioration caused by reinforcement corrosion," ACI Structural Journal, vol. 102, no. 5, pp. 754-762, 2005.

[3] L. Basheer, J. Kropp, and D. J. Cleland, "Assessment of the durability of concrete from its permeation properties: a review," Construction and Building Materials, vol. 15, no. 2-3, pp. 93-103, 2001.

[4] M. Chemrouk and T. Tahenni, "Étude des flèches et des ouvertures de fissures des poutres en béton arme contenant des fibres d'acier," in Proceedings of the 1st International Conference on Sustainable Built Environment Infrastructures in Developing Countries ENSET (SBEIDCO '09), p. 1, Oran, Algeria, 2009.

[5] G. Malumbela, P. Moyo, and M. Alexander, "Behaviour of RC beams corroded under sustained service loads," Construction and Building Materials, vol. 23, no. 11, pp. 3346-3351, 2009.

[6] Z. Z. Rijal, A. B. Abd Rahman, R. N. Mohamed, I. S. Ibrahim, and S. Z. Sooria, "Comparison of bond stresses of deformed steel bars embedded in two different concrete mixes," in Proceedings of the 9th Asia Pacific Structural Engineering \& Construction Conference (APSEC '15) and 8th Asean Civil Engineering Conference (ACEC '15), pp. 131-136, Kuala Lumpur, Malaysia, November 2015.

[7] X. He and D. Peng, "Experimental study on crack resistance property of fresh polypropylene fiber concrete," in Proceedings of the International Conference on Multimedia Technology (ICMT '11), pp. 1064-1069, IEEE, Hangzhou, China, July 2011.

[8] C. Q. Li, "Initiation of chloride-induced reinforcement corrosion in concrete structural members-experimentation," ACI Structural Journal, vol. 98, no. 4, pp. 502-510, 2001.

[9] C. Q. Li, "Initiation of chloride-induced reinforcement corrosion in concrete structural members-prediction," ACI Structural Journal, vol. 99, no. 2, pp. 133-141, 2002.

[10] C. Q. Li and R. E. Melchers, "Time-dependent reliability analysis of corrosion-induced concrete cracking," ACI Structural Journal, vol. 102, no. 4, pp. 543-549, 2005.

[11] Z. X. Chen Jinping, The Study on the Durability of the Concrete Structure, IEEE, Piscataway, NJ, USA, 2010.

[12] L. Schueremans, D. Van Gemert, and S. Giessler, "Chloride penetration in RC-structures in marine environment-long term assessment of a preventive hydrophobic treatment," Construction and Building Materials, vol. 21, no. 6, pp. 1238-1249, 2007.

[13] J. Pommersheim and J. Clifton, "Prediction of concrete servicelife," Materials and Structures, vol. 18, no. 1, pp. 21-30, 1985.
[14] N. Verma and A. K. Misra, "Bond characteristics of reinforced TMT bars in self compacting concrete and normal cement concrete," Alexandria Engineering Journal, vol. 54, no. 4, pp. 1155-1159, 2015.

[15] F. M. De Almeida Filho and A. L. H. D. C. El Debs, "Numerical approach of the bond stress behavior of steel bars embedded in self-compacting concrete (SCC) and in ordinary concrete in pullout models," Science and Engineering Journal, vol. 23, no. 2, pp. 57-66, 2014.

[16] M. R. Kabir and M. M. Islam, "Bond stress behavior between concrete and steel rebar: critical investigation of pull-out test via Finite Element Modeling," International Journal of Civil And Structural Engineering, vol. 5, no. 1, pp. 80-90, 2014.

[17] M. N. S. Hadi, "Bond of high strength concrete with high strength reinforcing steel," Magazine of Concrete Research, vol. 56, no. 9, pp. 545-557, 2004.

[18] F. Yan, Z. Lin, and M. Yang, "Bond mechanism and bond strength of GFRP bars to concrete: a review," Composites Part B: Engineering, vol. 98, pp. 56-69, 2016.

[19] A. M. Diab, H. E. Elyamany, M. A. Hussein, and H. M. Al Ashy, "Bond behavior and assessment of design ultimate bond stress of normal and high strength concrete," Alexandria Engineering Journal, vol. 53, no. 2, pp. 355-371, 2014.

[20] X. Fu and D. D. L. Chung, "Improving the bond strength between steel rebar and concrete by ozone treatment of rebar and polymer addition to concrete," Cement and Concrete Research, vol. 27, no. 5, pp. 643-648, 1997.

[21] A. Foroughi-Asl, S. Dilmaghani, and H. Famili, "Bond strength of reinforcement steel in self-compacting concrete," International Journal of Civil Engineerng, vol. 6, no. 1, pp. 24-33, 2008.

[22] Y. Shi and X. Li, "Analysis of ductility of composite steelconcrete structure based on computer simulation technology," in Proceedings of the 7th International Conference on Measuring Technology and Mechatronics Automation (ICMTMA '15), pp. 141-144, June 2015.

[23] L. Marsavina, K. Audenaert, G. De Schutter, N. Faur, and D. Marsavina, "Experimental and numerical determination of the chloride penetration in cracked concrete," Construction and Building Materials, vol. 23, no. 1, pp. 264-274, 2009. 


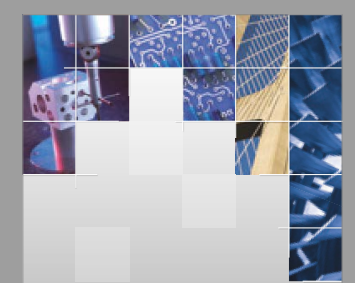

\section{Enfincering}
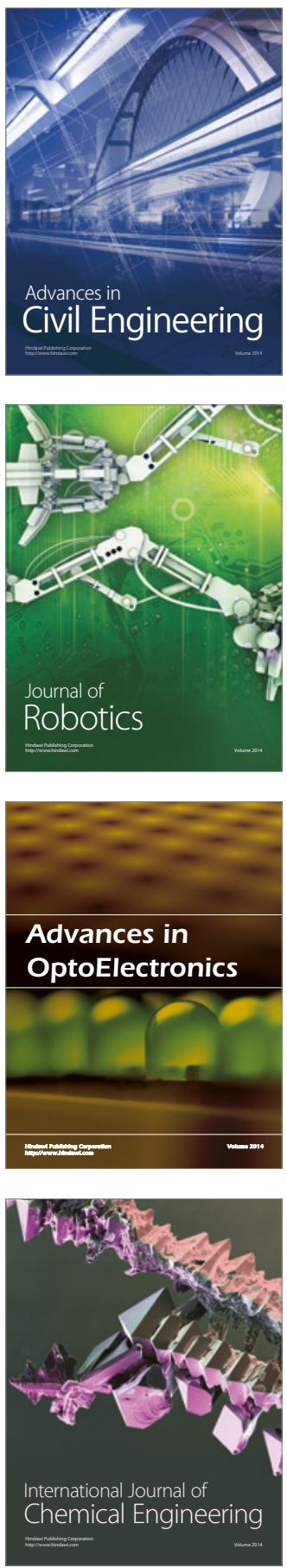

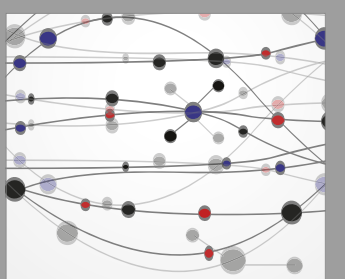

The Scientific World Journal

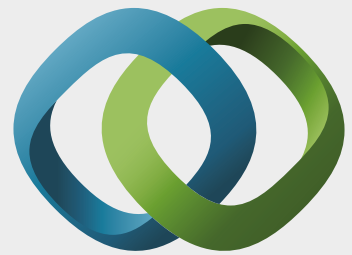

\section{Hindawi}

Submit your manuscripts at

https://www.hindawi.com
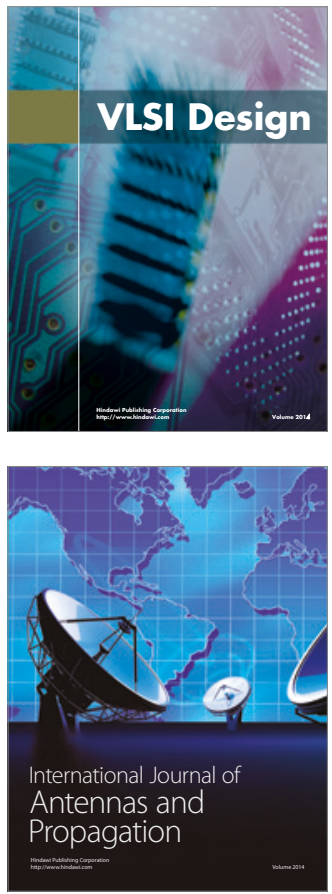

\section{Rotating}

Machinery
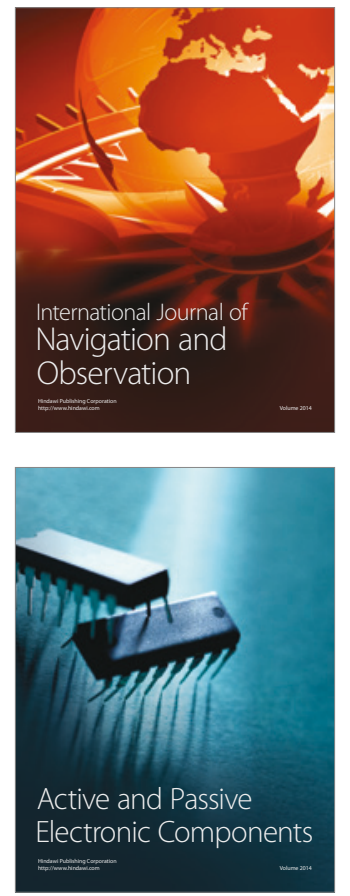
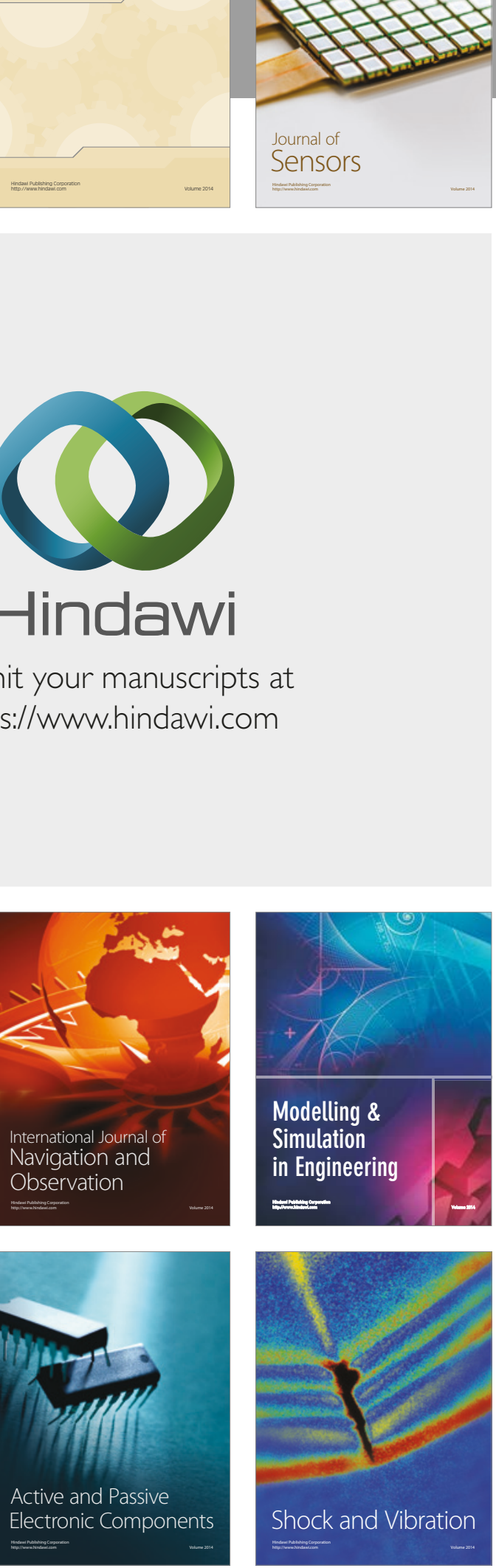
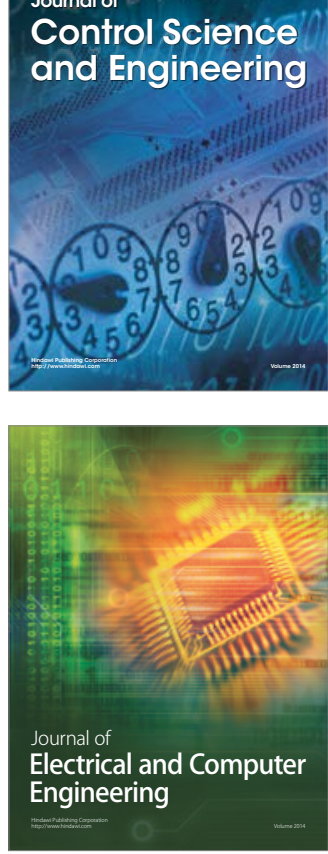

Distributed

Journal of

Control Science

and Engineering
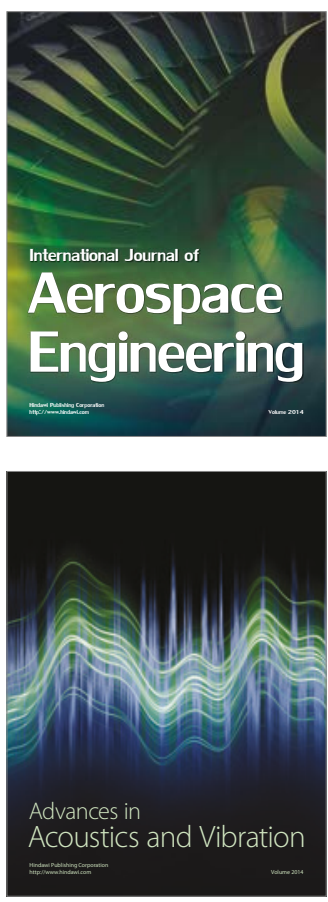

Sensor Networks 